\title{
Intrauterine Candida albicans infection elicits severe inflammation in fetal sheep
}

Matthew S. Payne', Matthew W. Kemp' , Suhas G. Kallapur ',2, Paranthaman Senthamarai Kannan², Masatoshi Saito ${ }^{1,3}$, Yuichiro Miura ${ }^{1,3}$, John P. Newnham ${ }^{1}$, Sarah Stock ${ }^{1,4}$, Demelza J. Ireland' ${ }^{1}$, Boris W. Kramer ${ }^{1,5}$ and Alan H. Jobe ${ }^{1,2}$

BACKGROUND: Preventing preterm birth and subsequent adverse neonatal sequelae is among the greatest clinical challenges of our time. Recent studies suggest a role for Candida spp. in preterm birth and fetal injury, as a result of their colonization of either the vagina and/or the amniotic cavity. We hypothesized that intraamniotic Candida albicans would cause a vigorous, acute fetal inflammatory response.

METHODS: Sheep carrying singleton pregnancies received single intraamniotic injections of either saline (control) or $10^{7}$ colony-forming units $C$. albicans 1 or $2 \mathrm{~d}$ prior to surgical delivery and euthanasia at $124 \pm 2 \mathrm{~d}$ gestation.

RESULTS: Colonization of the amniotic cavity by C. albicans resulted in a modest inflammatory response at $1 \mathrm{~d}$ and florid inflammation at $2 \mathrm{~d}$, characterized by fetal thrombocytopenia, lymphopenia, and significant increases of inflammatory cytokines/chemokines in the fetal membranes skin, lung, and the amniotic fluid.

CONCLUSION: Acute colonization of the amniotic cavity by C. albicans causes severe intrauterine inflammation and fetal injury. C. albicans is a potent fetal pathogen that can contribute to adverse pregnancy outcomes.

$\mathbf{P}$ reterm birth remains a leading cause of neonatal mortality and morbidity worldwide. Although the causes of preterm birth are multifactorial, infection of the amniotic cavity and subsequent intrauterine inflammation are both strongly associated with preterm delivery and adverse neonatal outcomes (including respiratory, gastrointestinal, and neurological injuries), most notably in deliveries occurring at $\leq 32 \mathrm{wk}$ completed gestation $(1,2)$. Culture- and molecular-based analyses have identified bacterial genera including Ureaplasma, Fusobacterium, Streptococcus, Bacteroides, and Gardnerella spp. as the microorganisms most commonly isolated from preterm deliveries $(1,3)$. Recent studies suggest that many of the intrauterine infections associated with preterm labor are polymicrobial in nature $(3,4)$.

Historically, the role of Candida spp. in preterm birth and neonatal injury has been somewhat unclear. However, recent molecular data suggest that Candida albicans may colonize the amniotic cavity more frequently than initially suggested by culture-based analyses, and cases of congenital candidiasis have been reported in the literature (5-8). Rode et al. (9) have suggested a possible association between serial amniocenteses and Candida chorioamnionitis. More recently, Bean et al. (10) published the resolution of two cases of intraamniotic $C$. albicans infection with maternal and intraamniotic fluconazole. Key conclusions of this case report were that intraamniotic C. albicans infection has devastating implications for the fetus and that prompt diagnosis and treatment of infection is essential for pregnancy wellbeing.

Candida spp. (most commonly C. albicans) are believed to asymptomatically colonize the vagina of $20 \%$ of healthy women (more frequently during pregnancy), and invasive candidiasis can be a primary cause of death and neurological injury in extremely low-birth-weight infants $(<1,000 \mathrm{~g})$ $(3,11,12)$. Although a causal association for bacterial infection in early preterm labor is well established, the role of Candida spp. in uterine infection and preterm delivery is more controversial $(3,12)$. A large multicentre study of pregnancy outcomes and Candida spp. colonization in 13,914 women concluded that colonization with Candida spp. was not associated with low birth weight or preterm delivery (13). In direct contrast, a retrospective study of 38,151 infants, identified a $34-64 \%$ reduction in preterm birth in a subset $(8.1 \%)$ born to mothers that received Clotrimazole (anti-Candida spp.) treatment during pregnancy (14). In addition, more recent smaller intervention studies reported either a significant reduction or a trend to reduction in preterm birth in groups receiving treatment for asymptomatic vaginal candidiasis $(12,15)$. Of particular interest is research suggesting an apparent association between indwelling contraceptives and cervical cerclage with Candida spp. infection of the amniotic cavity (3).

We have previously utilized pregnant sheep to investigate the effects of Escherichia coli lipopolysaccharides (16), antenatal corticosteroids (17), interleukin (IL)-1 (18), and live Ureaplasma spp. (19) on the fetal lung (20), gut (21), and skin

The first two authors contributed equally to this work.

'School of Women's and Infants' Health, The University of Western Australia, Perth, Australia; 'Division of Pulmonary Biology, Cincinnati Children's Hospital Medical Center, University of Cincinnati School of Medicine, Cincinnati, Ohio; ${ }^{3}$ Division of Perinatal Medicine, Tohoku University Hospital, Sendai, Japan; ${ }^{4}$ MRC Centre for Reproductive Health, Queen's Medical Research Institute, University of Edinburgh, Edinburgh, UK; ${ }^{5}$ Department of Paediatrics, School of Oncology and Developmental Biology, Maastricht University Medical Center, Maastricht, The Netherlands. Correspondence: Matthew W. Kemp (matthew.kemp@uwa.edu.au) 
(22) and modulation of the fetal immune system (23). In light of emerging clinical data, animal studies are now needed to clarify the impact of acute intraamniotic C. albicans infection. To that end, we tested the pathogenicity of acute intrauterine C. albicans infection in a sheep model of human pregnancy. We hypothesized that intraamniotic $C$. albicans would cause a vigorous, acute fetal inflammatory response.

\section{RESULTS}

Intrauterine infection with $10^{7}$ colony-forming units (CFU) C. albicans resulted in florid intrauterine inflammation at $2 \mathrm{~d}$ postinfection. Limited histological changes in skin and lung, and relatively modest increases in cytokine/chemokine expression were detected in fetal tissues collected $1 \mathrm{~d}$ postinfection.

\section{Detection of Viable C. albicans}

Amniotic fluid from all $1 \mathrm{~d}$ and $2 \mathrm{~d}$ C. albicans exposed animals but none of the controls were positive for viable C. albicans growth (data not shown). qPCR analysis demonstrated

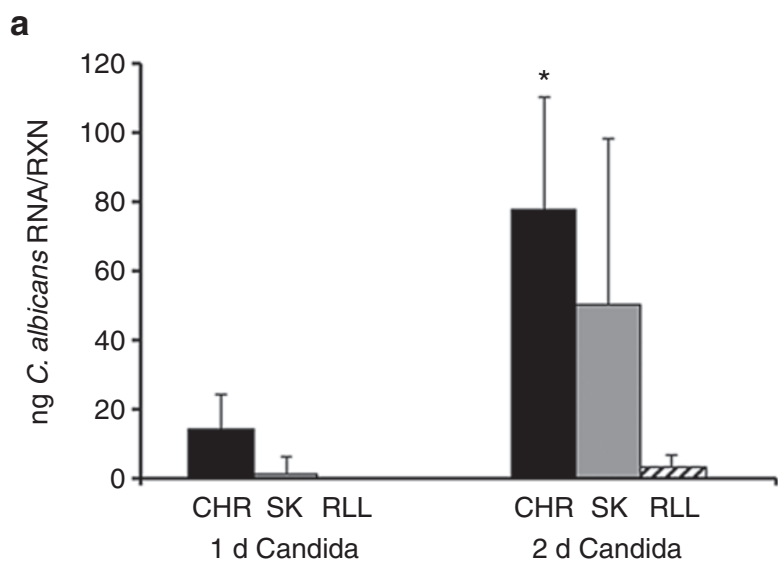

b

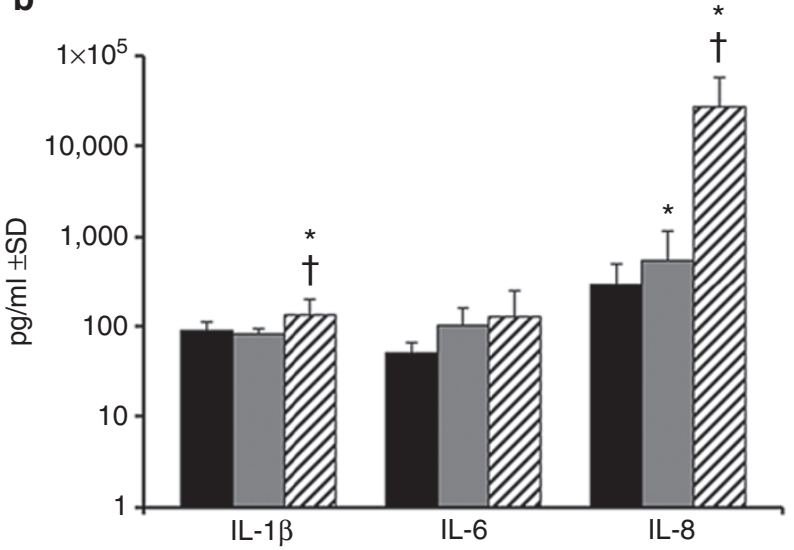

Figure 1. (a) Candida albicans RNA in fetal tissues in $1 \mathrm{~d}$ and $2 \mathrm{~d}$ postinfection groups ( $1 \mathrm{~d}$ Candida $n=5 ; 2 \mathrm{~d}$ Candida $n=5$ ). CHR, chorioamnion; $\mathrm{RLL}$, right lower lobe of lung; RXN, reaction; SK, skin. *Significant difference $(P<0.010)$ vs. RLL. (b) Concentration of interleukin (IL)-1 $\beta$ (black bars, control $n=10$; gray bars, $1 \mathrm{~d}$ Candida $n=8$; hatched bars, $2 \mathrm{~d}$ Candida $n=8$ ) and IL-8 (black bars, control $n=6$; gray bars, $1 \mathrm{~d}$ Candida $n=6$; hatched bars, $2 \mathrm{~d}$ Candida $n=6$ ), but not IL-6 (black bars, control $n=6$; gray bars, $1 \mathrm{~d}$ Candida $n=6$; hatched bars, $2 \mathrm{~d}$ Candida $n=6$;) is increased in AF in response to intraamniotic injection with $C$. albicans. ${ }^{*} P<0.05$ vs. control; ${ }^{+} P<0.05$ vs. $1 \mathrm{~d}$ C. albicans exposure. increased C. albicans RNA in fetal lung $(3.8 \pm 3 \mathrm{ng})$, chorioamnion $(78 \pm 32 \mathrm{ng})$, and skin $(50 \pm 48 \mathrm{ng})$ taken from animals exposed to C. albicans for $2 \mathrm{~d}$, relative to fetal lung $(0.2 \pm 0.1 \mathrm{ng})$, chorioamnion ( $14 \pm 10 \mathrm{ng})$, and skin $(6.0 \pm 5.0 \mathrm{ng})$ exposed to C. albicans for $1 \mathrm{~d}$ (Figure 1a). The highest levels of C. albicans RNA were detected in chorioamnion tissue after a $2 \mathrm{~d}$ exposure $(P<0.010$ vs. $2 \mathrm{~d}$ fetal lung). No C. albicans RNA was detected in the fetal spleen after either $1 \mathrm{~d}$ or $2 \mathrm{~d} C$. albicans exposure or in any saline control animal.

\section{Cytokine/Chemokine Protein Concentration in Fetal Plasma, Amniotic Fluid, and Fetal Lung Fluid}

No changes in IL-1 $\beta$, IL- 6 , or IL- 8 protein concentration were detected in fetal plasma from animals exposed to C. albicans for either 1 or $2 \mathrm{~d}$, relative to control (data not shown). Analysis of IL-1 $\beta$, IL-6, and IL-8 protein concentrations in the amniotic fluid (AF) demonstrated significant increases in the concentration of: (i) IL-1 $\beta$ in $2 \mathrm{~d} C$. albicans exposed animals relative to $1 \mathrm{~d} C$. albicans exposed animals $(P=0.007)$ and control $(P=0.003)$ and (ii) IL-8 in $2 \mathrm{~d}$ C. albicans exposed animals relative to $1 \mathrm{~d}$ C. albicans exposed animals $(P=0.044)$ and control $(P=0.046)$. No significant change in IL-6 concentration was detected (Figure 1b). Analysis of IL-1 $\beta$, IL-6, and IL-8 protein concentration in fetal lung fluid demonstrated significant increases in the concentration of: (i) IL-1 $\beta$ in $2 \mathrm{~d}$ C. albicans exposed animals relative to control ( $680 \pm 900$ vs. $157 \pm 10 \mathrm{pg} / \mathrm{ml} ; P=0.048)$ and (ii) IL-8 in $2 \mathrm{~d}$ C. albicans exposed animals, relative to control ( $20 \pm 18.5$ vs. $1.4 \pm 2.0 \mathrm{ng} / \mathrm{ml} ; P=0.002)$. No significant change in fetal lung fluid IL-6 concentration was detected (data not shown).

\section{Elevated Circulating Fetal Cortisol}

Concentrations of cortisol in fetal arterial plasma demonstrated variable, but significant increases in concentration at $2 \mathrm{~d}$ postinfection relative to $1 \mathrm{~d}$ postinfection $(P=0.007)$ and control $(P=0.002)$ (Figure 2$)$.

\section{Hematological Analyses}

Complete/differential fetal blood counts demonstrated marked thrombocytopenia and leukopenia after $2 \mathrm{~d}$ intrauterine C. albicans infection (Table 1$)$; circulating platelets $(P=0.026)$

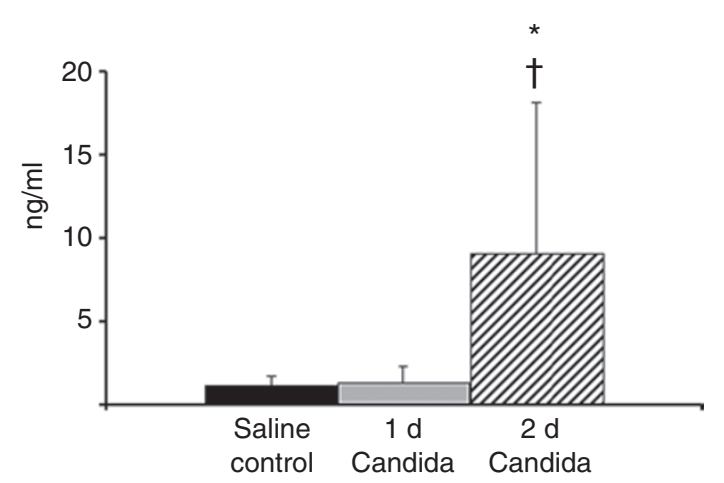

Figure 2. Concentration of fetal arterial plasma cortisol (control $n=13 ; 1 \mathrm{~d}$ Candida $n=8 ; 2 \mathrm{~d}$ Candida $n=8$ ) is increased in response to $2 \mathrm{~d}$ Candida albicans exposure vs. control. ${ }^{*} P<0.05$ vs. control; ${ }^{\dagger} P<0.05$ vs. $1 \mathrm{~d}$ C. albicans exposure. 


\section{Articles $\mid$ Payne etal.}

Table 1. Group, birth weight, and differential blood count summary data for control $(n=13)$ and $1 \mathrm{~d}(n=8)$ and $2 \mathrm{~d}(n=8)$ Candida postinfection groups

\begin{tabular}{|c|c|c|c|c|c|c|}
\hline Group & $n$ & Fetal weight $(\mathrm{kg})$ & Platelets $\left(10^{9} / \mathrm{l}\right)$ & Total white blood cells $\left(10^{11} / \mathrm{l}\right)$ & Monocytes $\left(10^{9} / l\right)$ & Lymphocytes $\left(10^{9} / \mathrm{l}\right)$ \\
\hline Saline & 13 & $2.8 \pm 0.3$ & $616 \pm 157$ & $2.83 \pm 1.3$ & $0.1 \pm 0.1$ & $1.90 \pm 1.0$ \\
\hline $1 \mathrm{~d}$ Candida & 8 & $3.1 \pm 0.4$ & $576 \pm 63$ & $3.50 \pm 1.0$ & $0.2 \pm 0.01$ & $2.30 \pm 1.0$ \\
\hline 2 d Candida & 8 & $2.9 \pm 0.2$ & $437 \pm 170^{*}$ & $1.50 \pm 1.1^{*}$ & $0.2 \pm 0.10$ & $0.90 \pm 0.80^{+}$ \\
\hline
\end{tabular}

${ }^{*} P<0.05$ vs. control; $+P<0.05$ vs. $1 \mathrm{~d}$ Candida postinfection group.
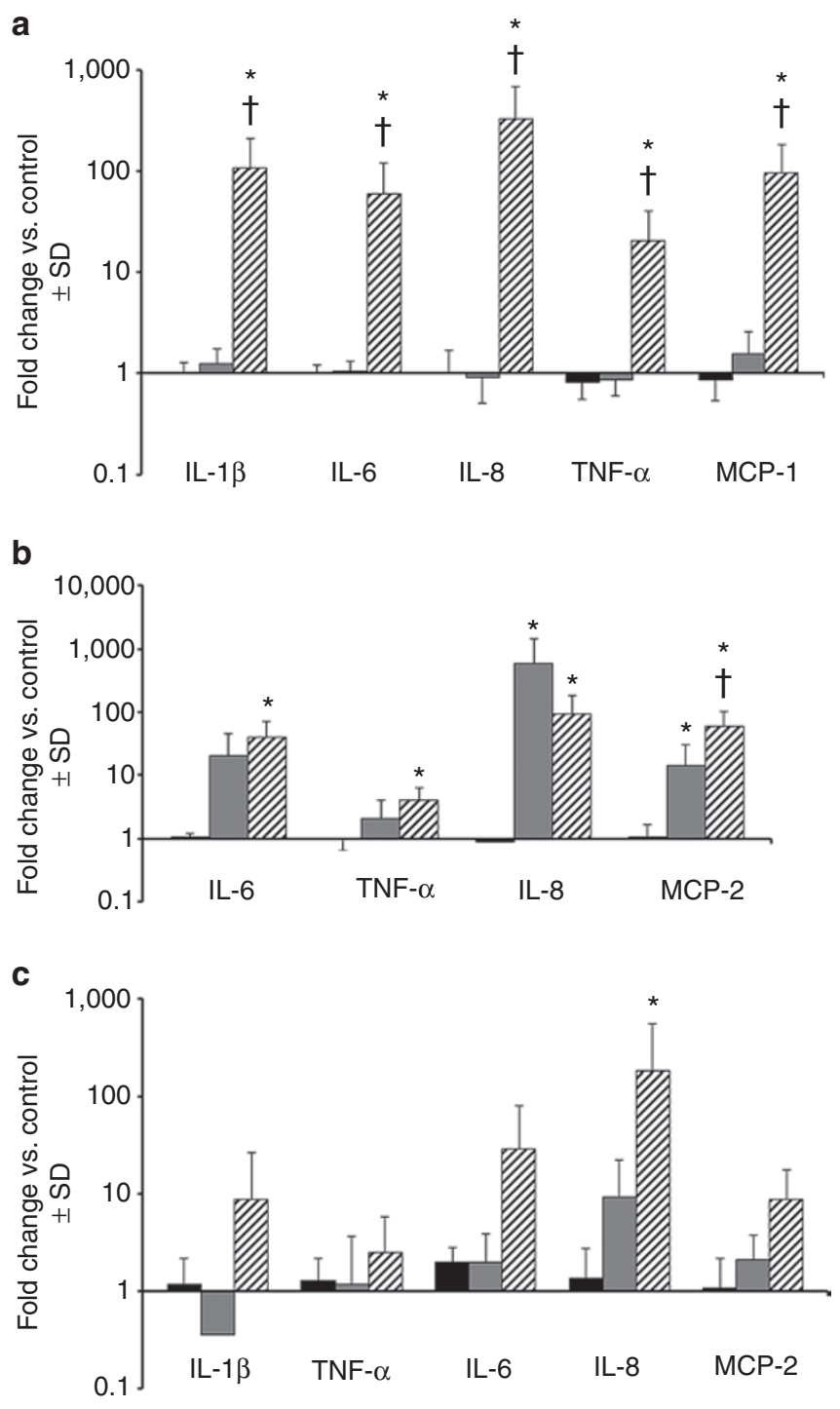

Figure 3. (a) Expression of cytokine/chemokine mRNA is increased in the fetal lung in response to $2 \mathrm{~d}$ Candida albicans exposure. Black bars, control $n$ $=13$; gray bars, $1 \mathrm{~d}$ Candida $n=8$; hatched bars, $2 \mathrm{~d}$ Candida $n=8 .{ }^{*} P<0.05$ vs. control; ${ }^{\dagger} P<0.05$ vs. $1 \mathrm{~d}$ C. albicans exposure. (b) Expression of cytokine/ chemokine mRNA is variably increased in the fetal skin in response to $1 \mathrm{~d}$ and $2 \mathrm{~d}$ C. albicans exposure. Black bars, control $n=6$; gray bars, $1 \mathrm{~d}$ Candida $n$ $=5$; hatched bars, $2 \mathrm{~d}$ Candida $n=6{ }^{*} P<0.05$ vs. control; ${ }^{\dagger} P<0.05$ vs. $1 \mathrm{~d} C$. albicans exposure. (c) Only IL-8 is significantly increased in the chorioamnion in response to $1 \mathrm{~d}$ and $2 \mathrm{~d}$ C. albicans exposure. Black bars, control $n=6$; gray bars, $1 \mathrm{~d}$ Candida $n=6$; hatched bars, $2 \mathrm{~d}$ Candida $n=5$. ${ }^{*} P<0.05$ vs. control.

and white blood cells $(P=0.006)$ were significantly reduced relative to control. Lymphocytes at $2 \mathrm{~d}$ postinfection were significantly reduced relative to counts at $1 \mathrm{~d}$ postinfection
$(P=0.015)$ and an apparent reduction relative to control counts closely approached significance $(P=0.08)$.

\section{Elevated Cytokine/Chemokine mRNA Expression in the Fetal Lung, Skin, and Membranes}

Analysis of cytokine/chemokine expression in the fetal lung, skin, and membranes identified a pattern of significant mRNA upregulation at $2 \mathrm{~d}$ post-C. albicans infection, relative to both control and $1 \mathrm{~d}$ post-C. albicans infection tissues. Significant increases in IL-1 $\beta(P=0.007)$, IL-6 $(P=0.007)$, IL-8 $(P=0.010)$, tumor necrosis factor $(\mathrm{TNF})-\alpha(P=0.003)$, and monocyte chemoattractant protein (MCP)-1 $(P=0.003)$ mRNA expression were identified in the fetal lung at $2 \mathrm{~d}$ postinfection, relative to control (Figure 3a). In the fetal skin, significant mRNA increases were observed in the expression of IL- 6 at $2 \mathrm{~d}(P=$ $0.004)$, TNF- $\alpha$ at $2 \mathrm{~d}(P=0.019)$, IL- 8 at $1 \mathrm{~d}(P=0.000)$ and $2 \mathrm{~d}$ $(P=0.000)$, and MCP- 2 at $1 \mathrm{~d}(P=0.031)$ and $2 \mathrm{~d}(P=0.000)$ post- $C$. albicans infection, relative to control (Figure $3 b$ ). In fetal membranes, a significant increase was only observed in IL-8 mRNA expression $(P=0.020)$ at $2 \mathrm{~d}$ post- $C$. albicans infection, relative to control (Figure $3 \mathrm{c}$ ).

\section{Histological Analysis of the Fetal Lung and Skin}

Seven of eight fetal lung samples from the $2 \mathrm{~d}$ Candida group assessed for inflammation and consolidation were graded $2(n=4)$ or $3(n=3)$ (Figure 4a-c), consistent with robust inflammation of the fetal lung. A marked increase in C. albicans staining intensity and distribution was apparent in lung tissues taken from $2 \mathrm{~d} \mathrm{C}$. albicans-exposed animals, relative to $1 \mathrm{~d}$ C. albicans-exposed and saline control animals (Figure 4a-c insert). CD3-positive cells were significantly increased ( $33.0 \pm 8.0$ vs. $12.0 \pm 4.0$ cells/low-power field; $P=$ 0.006) in the fetal lung of animals exposed to C. albicans for $2 \mathrm{~d}$, relative to control (Figure 4d). Hemotoxylin and eosin staining of transverse fetal skin sections demonstrated numerous foci of basophilic infiltration of the stratum corneum at $2 \mathrm{~d}$ postinfection (Figure 5a). Immunofluorescent analysis of IL-8 expression in the fetal skin demonstrated distinct increases in signal intensity and distribution in $1 \mathrm{~d}$ and $2 \mathrm{~d}$ C. albicansexposed tissues, relative to control (Figure $5 b$ ).

\section{DISCUSSION}

Comparatively, little animal data are available to describe the inflammatory response to acute $C$. albicans colonization of the amniotic cavity (24-26). We present novel data demonstrating: (i) the colonization of the amniotic environment by $C$. albicans following intraamniotic infection and (ii) that intrauterine infection with $C$. albicans rapidly progresses to 
a

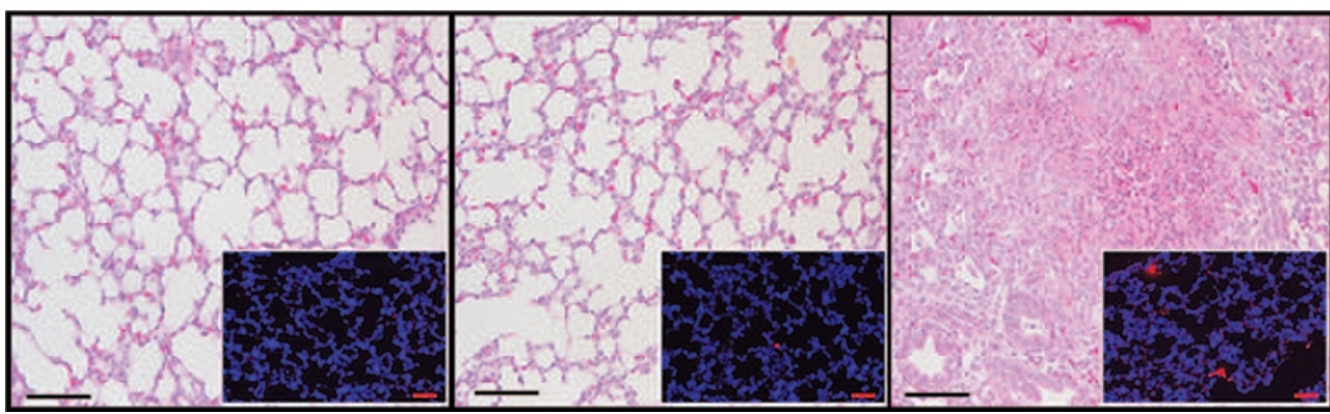

d

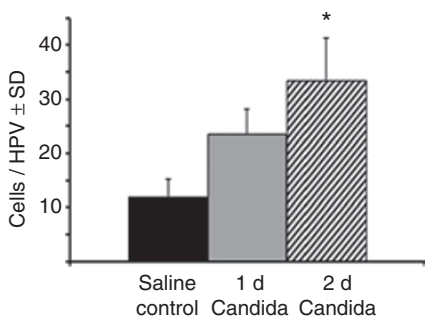

Figure 4. Infiltration and consolidation of the fetal lung in response to $2 \mathrm{~d}$ Candida albicans exposure (control $n=13 ; 1 \mathrm{~d}$ Candida $n=8 ; 2 \mathrm{~d}$ Candida $n=8$ ). (a) Control; (b) $1 \mathrm{~d}$ C. albicans exposure; and (c) 2 d C. albicans exposure. Inserts: Immunofluorescent staining for cell nuclei (4',6-diamidino-2-phenylindole dihydrochloride; blue) and C. albicans (Alexa 594; red). All scale bars represent $50 \mu \mathrm{m}$. (d) Analysis of infiltration of fetal lung by CD3-positive cells in response to colonization with C. albicans (control $n=6 ; 1 \mathrm{~d}$ Candida $n=5 ; 2 \mathrm{~d}$ Candida $n=5$ ). ${ }^{*} P<0.05$ vs. control. HPV, high-power view.
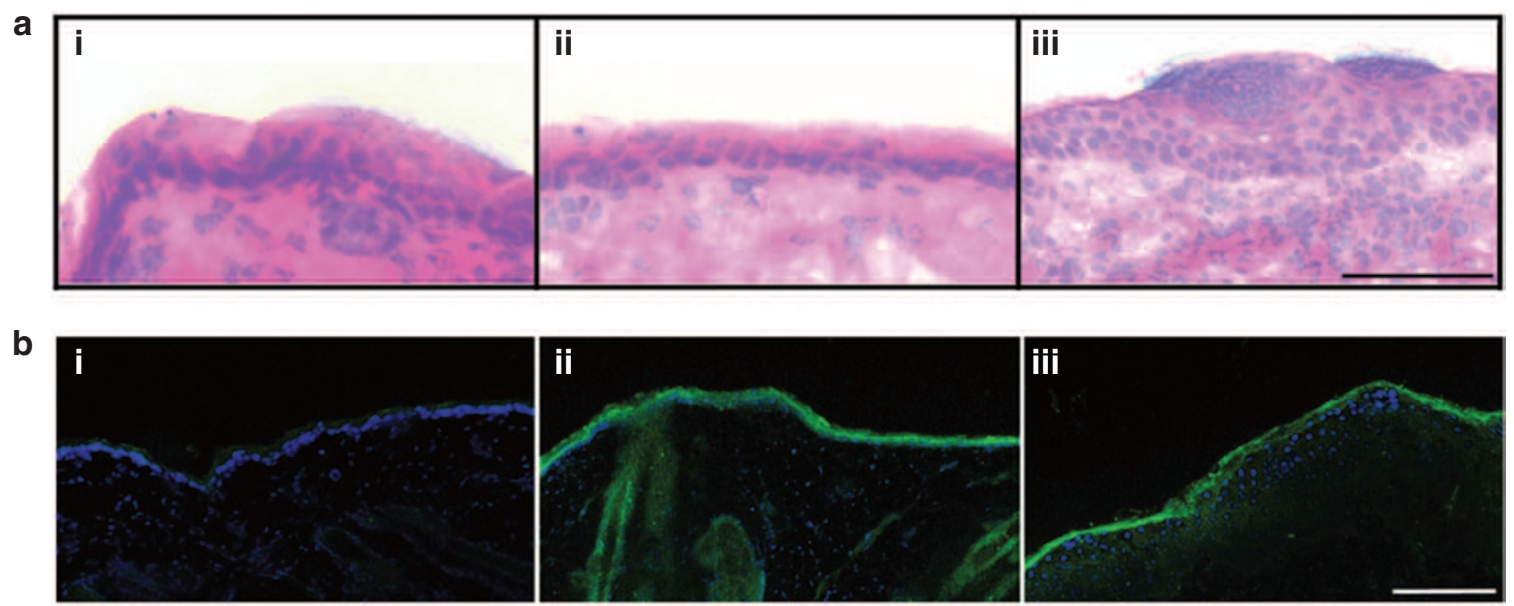

Figure 5. (a) Infiltration of the fetal skin in response to Candida albicans exposure (control $n=5 ; 1 \mathrm{~d}$ Candida $n=5 ; 2 \mathrm{~d}$ Candida $n=5$ ). i: Control; ii: $1 \mathrm{~d}$ C. albicans exposure; and iii: $2 \mathrm{~d}$ C. albicans exposure. Scale bar represents $50 \mu \mathrm{m}$. (b) Relative to control, immunofluorescent staining for IL-8 (Alexa 488; green) is increased in the fetal dermis and epidermis after $1 \mathrm{~d}$ and $2 \mathrm{~d}$ C. albicans exposure. i: Control $n=5$ ii: $1 \mathrm{~d}$ Candida $n=5$; iii: $2 \mathrm{~d}$ Candida $n=5$. Cell nuclei are stained blue with 4',6-diamidino-2-phenylindole dihydrochloride. Scale bar represents $200 \mu \mathrm{m}$.

an active infection involving multiple fetal surfaces yielding florid intrauterine inflammation and depletion of circulating fetal immunocytes and platelets. These findings add weight to recent clinical reports concluding that the prompt diagnosis and treatment of intraamniotic C. albicans infection is critical to pregnancy wellbeing (10).

Infection of the amniotic cavity with C. albicans was characterized by a quasilatent period of at least $1 \mathrm{~d}$ postinfection. Although significant increases in IL-6, IL-8, and MCP-2 mRNA transcript expression were identified in the fetal skin and IL-8 protein concentration in the AF at $1 \mathrm{~d}$ postinfection, no changes were identified in lung or chorioamnion mRNA expression, fetal arterial plasma cortisol levels, or fetal white blood cell counts. At $2 \mathrm{~d}$ postinfection, significant increases in mRNA expression were detected in the fetal skin and lung, with a limited (IL-8 only) response detected in the chorioamnion.

Cytokine/chemokine mRNA expression in the fetal skin and lung, and cytokine protein concentrations in the fetal lung fluid correlated with increased C. albicans RNA levels at $2 \mathrm{~d}$. Interestingly, the vigorous inflammatory response identified in the fetal lung in the $2 \mathrm{~d}$ postinfection group was disproportionate to the comparatively low level of C. albicans RNA detected. Conversely, the inflammatory response detected in the chorioamnion was comparatively mild (given the high levels of $C$. albicans RNA isolated from this tissue) at both 1 and $2 \mathrm{~d}$. These data suggest a differential sensitivity between tissues (lung, skin, and chorioamnion) to inflammatory stimulation by C. albicans. Surprisingly, no C. albicans RNA was detected in the fetal spleen in either the 1 or $2 \mathrm{~d}$ postinfection groups. Although we did not extensively culture from aseptically harvested fetal organs, these molecular data indicate that C. albicans does not gain access to the fetal circulation by $2 \mathrm{~d}$ despite significant colonization of the fetal lung and skin. This observation also suggests that the systemic changes (alterations in leukocyte counts and fetal arterial plasma) identified in this study are due to inflammatory signaling derived from AF-exposed skin/amnion and lung. Using chronically instrumented preterm lambs, we have previously demonstrated the importance of the fetal lung to acute systemic inflammation (27). Those findings are supported by data in the present study, 
which also suggest that fetal lung inflammation is a key mediator of a systemic fetal response. Additionally, our data also suggest that inflammation of the fetal skin/chorioamnion, in the absence of fetal lung inflammation, is sufficient to increase cytokine (IL-8) concentrations in the AF. Although not investigated in the present study, it would be of great interest to assess the inflammatory and structural changes deriving from colonization of the fourth AF-exposed fetal surface, the gastrointestinal tract, by C. albicans.

Our data also contrast with earlier lipopolysaccharidebased studies in this model, wherein intraamniotic injection of $10 \mathrm{mg}$ lipopolysaccharides resulted in broad increases in mRNA expression in both the fetal lung and chorioamnion at $1 \mathrm{~d}$ postinjection (28). The isolation of fetal inflammatory response to the skin at $1 \mathrm{~d}$ post- $C$. albicans infection may derive from the complete exposure of the fetal skin to the AF and C. albicans preference to this epithelial surface (29). It may also reflect a temporal difference in inflammatory response between skin and chorioamnion in the sheep. Interestingly, the magnitude and scope of inflammatory response elicited by $2 \mathrm{~d}$ infection with C. albicans was much greater than that identified in previous studies in fetal sheep involving E. coli lipopolysaccharide or Ureaplasma spp. over a similar time frame $(22,30,31)$.

The marked increase in fetal cortisol identified in the $2 \mathrm{~d}$ postinfection group is consistent with a robust fetal inflammatory response (32) and is similar in relative size to that demonstrated by Challis et al. (33) in chronically catheterized fetal sheep immediately prior to parturition; chorioamnionitis and elevated levels of IL-1 $\beta$ and IL- 6 have also been demonstrated to increase fetal cortisol production, inducing fetal lung maturation, and reduced birth weight $(32,34)$.

Thrombocytopenia is a salient feature of congenital and neonatal candidiasis $(35,36)$; an especially striking feature of $2 \mathrm{~d} C$. albicans infection in the present study was a marked reduction in fetal platelets. In contrast to our $2 \mathrm{~d}$ findings, however, congenital candidiasis is associated with a marked increase in total white blood cells $(5,6)$. This difference may relate to species- or gestation-dependent responses to $C$. albicans infection or be a function of the acute $(2 \mathrm{~d})$ nature of our experimental model.

Limitations of this study include the acute time frame over which the impact of $C$. albicans infection was assessed and that the infection was established by intraamniotic injection as opposed to ascending vaginal infection and penetration of the fetal membranes, the hypothesized route of the majority of intrauterine infections in humans (2). Further studies, potentially employing a low-titer inoculum and subchorionic infection to mimic ascending infection via a focal breach in the fetal membranes (37), are warranted to advance our understanding of the pathogenic role played by C. albicans in pregnancy.

\section{Conclusions}

An increasing number of clinical studies now suggest a role for Candida spp. in preterm birth and fetal injury. Our data support the recently published findings of Bean et al. (10) and further suggest a likely role for $C$. albicans in preterm birth and chorioamnionitis. Importantly, our data demonstrate that an untreated acute infection of the amniotic cavity with C. albicans can cause a devastating, florid fetal inflammatory response that is consistent with adverse neonatal outcomes. Additional animal and clinical studies are warranted to further assess the role of Candida spp. in preterm birth and fetal injury, the potential benefits of Candida spp. screening, and the best means of administering prophylaxis and treatment in pregnancy.

\section{METHODS}

\section{Animals}

All procedures involving animals were performed at The University of Western Australia (Perth, Australia) following review and approval by the animal care and use committees of The University of Western Australia and Cincinnati Children's Hospital (Cincinnati, $\mathrm{OH}$ ). Twenty-nine date-mated Australian merino ewes with singleton pregnancies were randomized to receive either: (i) a single ultrasoundguided intraamniotic injection of $2 \mathrm{ml}$ saline $(n=13)$ or (ii) a single ultrasound-guided intraamniotic injection of $10^{7} \mathrm{CFU}$ C. albicans (Western Australian clinical isolate) in $2 \mathrm{ml}$ saline with delivery after $1 \mathrm{~d}$ ( 1 d Candida group; $n=8$ ) or $2 \mathrm{~d}$ ( $2 \mathrm{~d}$ Candida group; $n=8$ ). Successful placement of intraamniotic injections were confirmed with electrolyte $\left(\mathrm{Cl}^{-}\right)$analysis of AF using a Siemens Rapidlab 1265 Analyzer (Siemens, Munich, Germany). No fetal losses occurred in the $1 \mathrm{~d}$ Candida, $2 \mathrm{~d}$ Candida, or saline control groups.

Fetuses were surgically delivered at $124 \pm 2 \mathrm{~d} \mathrm{GA}$, and euthanized with intravenous pentobarbitone $(100 \mathrm{mg} / \mathrm{kg})$. Fetal lung fluid and tissues for protein and mRNA expression analyses were collected at autopsy and snap frozen in liquid nitrogen. To eliminate a potential sampling bias, fetal skin was selectively collected from the fetal groins. A minimum of five, randomly selected animals were analyzed from each group. Fetal lung tissues for histological analysis were inflation fixed in $10 \%$ neutral buffered formalin for $24 \mathrm{~h}$ before paraffin embedding. Fetal skin tissues for histological analysis were cryopreserved in optimum cutting temperature compound.

\section{C. albicans Culture for Intraamniotic Injection}

A single Western Australian clinical isolate of C. albicans was cultured on Difco Sabaraud-Dextrose agar (Becton Dickinson, Franklin Lakes, $\mathrm{NJ})$ at $37^{\circ} \mathrm{C}$ for $48 \mathrm{~h}$ and single colonies were inoculated into sterile $1 \times$ phosphate-buffered saline (Sigma-Aldrich, St Loius, MO). C. albicans colony morphology was confirmed by growth on Brilliance Candida Agar (Oxoid, Adelaide, Australia). Inoculums were quantified using a plate dilution series as per standard microbiological methods and recorded as CFU/ml. Quantified inoculums $\left(10^{7} \mathrm{CFU}\right.$ in $2 \mathrm{ml} 1 \times$ phosphate-buffered saline) were stored at $-80^{\circ} \mathrm{C}$ prior to use.

\section{Nucleic Acid Extraction}

To develop a standard curve for quantitation of C. albicans in fetal tissues, total RNA was extracted from $250 \mu$ of C. albicans (the same Western Australian clinical isolate used in vivo in this study) using the Versant Sample Preparation kit 1.0 (Siemens) on a Kingfisher automated extraction platform (Thermo Scientific, Rockford, IL) as per manufacturer's instructions. Total RNA was extracted from liquid nitrogen-homogenized fetal tissues using TRIzol as previously reported (16). Extracted RNA was treated with Turbo-DNase (Life Technologies, Carlsbad, CA) to remove any residual DNA and subsequently quantified on a Qubit 2.0 fluorometer (Life Technologies) using a broad-range RNA quantitation kit (Life Technologies). RNA yields from fetal tissues were normalized to $100 \mathrm{ng} / \mu \mathrm{l}$ using nucleasefree water (Life Technologies).

\section{C. albicans Detection/Quantitation}

RNA extracted from fetal lung, skin, chorioamnion, and spleen was screened using a real-time PCR assay targeting the RNase P RNA gene of C. albicans (38). RNA-based reactions were performed using an EXPRESS One-Step SuperScript qRT-PCR Kit (Life Technologies) with $0.5 \mu \mathrm{mol} / \mathrm{l}$ each primer, $0.2 \mu \mathrm{mol} / \mathrm{l}$ probe, $400 \mathrm{ng}$ template RNA, and 
nuclease-free water to a final volume of $20 \mu$ l. To enable quantitation of C. albicans within each sample, a standard curve of pure C. albicans (study isolate) RNA was included in each assay at a final concentration of 40,4 , and $0.4 \mathrm{ng}$ per $20 \mu \mathrm{l}$ reaction. Reaction cycling conditions were as follows: $15 \mathrm{~min}$ reverse transcription at $50{ }^{\circ} \mathrm{C}$ and an initial denaturation at $95{ }^{\circ} \mathrm{C}$ for $20 \mathrm{~s}$, followed by 40 cycles of $95{ }^{\circ} \mathrm{C}$ for $3 \mathrm{~s}$ and $60^{\circ} \mathrm{C}$ for $30 \mathrm{~s}$. All reactions were performed in 96 well plates on a ViiA7 real-time PCR thermocycler (Life Technologies). The presence of viable $C$. albicans in AF samples was determined using a Sabaraud-Dextrose agar plate dilution series as described above. Three single colonies from positive plates were subsequently inoculated onto Candida Brilliance agar (Oxoid) for confirmation of isolate identification.

\section{Relative Quantification of mRNA Expression}

Ovine-specific PCR primers and hydrolysis probes for IL-1 $\beta$, IL-6, IL-8, TNF- $\alpha$, MCP-1, and MCP-2 (Life Technologies) were used to perform quantitative PCR reactions on RNA from fetal lung, skin, and chorioamnion tissue. Reactions were performed using an EXPRESS One-Step SuperScript qRT-PCR kit (Life Technologies) with $400 \mathrm{ng}$ template RNA in a total volume of $20 \mu$ l. Reaction cycling conditions were as described above. $C_{\mathrm{q}}$ values were normalized to $18 \mathrm{~S}$ rRNA and expressed as fold changes relative to pooled control values. Reaction efficiencies were within limits proposed in the MIQE guidelines (39).

\section{Enzyme-Linked Immunosorbent Assays}

Quantification of IL-1 $\beta$ and IL-8 protein concentrations in AF was performed as previously described (40). AF samples were diluted 1:5 in assay buffer. Quantification of IL-6 protein concentration in ovine $\mathrm{AF}$ was performed using an identical protocol with the following modifications: plate wells were coated overnight at $4{ }^{\circ} \mathrm{C}$ with $5 \mu \mathrm{g} / \mathrm{ml}$ capture antibody (MCA1659; ABD Serotech, Kidlington, UK). Recombinant sheep IL-6 protein standards (Protein Express, Cincinnati, $\mathrm{OH}$ ) and $\mathrm{AF}$ samples, diluted 1:2 in assay buffer, were incubated overnight at $4{ }^{\circ} \mathrm{C}$. The detection antibody (AHP424; ABD Serotech) was diluted 1:750 in assay buffer. All samples and standards were assayed in duplicate. Cortisol measurements were performed with a Cortisol EIA kit (Oxford Biomedical Research, Rochester Hills, MI) on 1:10 diluted fetal arterial cord blood plasma according to the manufacturer's instructions.

\section{Hematology}

Complete blood counts and differential analyses were performed with an automated Coulter counter customized for sheep blood.

\section{Histology}

Five-micrometer thick sections from formalin-fixed lung (right upper lobe) tissues embedded in paraffin blocks or $10-\mu \mathrm{m}$ thick sections from cryopreserved skin tissues embedded in OCT were stained with hematoxylin and eosin. For lung tissues, five random fields were scored for inflammatory cell infiltration and airspace consolidation as follows: 0: normal; 1: airspace inflammatory cells, no consolidation; 2: airspace inflammatory cells + microconsolidation focii (1-2/5 low power field); 3: airspace inflammatory cells + microconsolidation focii ( $\geq 3 / 5$ low-power field); and 4 : extensive airspace inflammatory cells and consolidation. Immunohistochemical staining of fetal lung for CD3 (A0452, Dako, Glostrup, Denmark, working concentration 1:100) and C. albicans (B65411R, Meridian Life Science, Memphis, $\mathrm{TN}$, working concentration 1:50) was performed as previously published (27). CD3 counts in fetal lung were obtained by counting positively stained cells in five randomly selected, nonoverlapping fields at $20 \times$ objective magnification.

\section{Statistical Analyses}

All values are expressed as mean \pm SD. All analyses were performed using IBM SPSS Statistics for Windows, software version 20.0 (IBM, Armonk, NY). Data were assessed for normality with Shapiro-Wilk tests and histograms. Parametric data were screened for outliers with Dixon's Q-parameter and differences tested for significance with oneway ANOVA employing an $\alpha$-value of 0.05 . Multiple post hoc comparisons were performed using Tukey's test. Apparent differences in nonparametric data were tested for significance with Kruskal-Wallis one-way ANOVA employing an $\alpha$-value of 0.05 . Multiple post hoc comparisons were performed using rank-sum tests with an $\alpha$-value corrected for $n$ multiple comparisons.

\section{ACKNOWLEDGMENTS}

The authors thank Pietro Presicce and Manuel Alvarez Jr. for expert technical assistance; Icon Agriculture (Darkan, Australia) for their expertise in datecritical animal breeding; and Siemens Australia for the generous donation of Rapidlab 1265 reagents and consumables. These findings were presented at the 65th Annual Meeting, Society for Gynaecologic Investigation, Orlando, FL, 18-21 March 2013 and the Pediatric Academic Societies Annual Meeting, Washington, DC, 4-7 May 2013.

\section{STATEMENT OF FINANCIAL SUPPORT}

This work was supported by National Institutes of Health (Bethesda, MD) grant HD57869 to S.K. and by grants from the Women and Infants Research Foundation (Australia) and the Financial Markets Foundation for Children (Australia) to M.W.K.

Disclosure: None declared.

\section{REFERENCES}

1. Agrawal V, Hirsch E. Intrauterine infection and preterm labor. Semin Fetal Neonatal Med 2012;17:12-9.

2. Goldenberg RL, Culhane JF, Iams JD, Romero R. Epidemiology and causes of preterm birth. Lancet 2008;371:75-84.

3. DiGiulio DB. Diversity of microbes in amniotic fluid. Semin Fetal Neonatal Med 2012;17:2-11.

4. Jones HE, Harris KA, Azizia M, et al. Differing prevalence and diversity of bacterial species in fetal membranes from very preterm and term labor. PLoS ONE 2009;4:e8205.

5. Darmstadt GL, Dinulos JG, Miller Z. Congenital cutaneous candidiasis: clinical presentation, pathogenesis, and management guidelines. Pediatrics 2000;105:438-44.

6. Gonçalves-Ferri WA, Sato DA, Ramalho FS, De Carvalho Panzeri Carlotti AP, Duarte G, Mussi-Pinhata MM. Congenital systemic candidiasis without skin lesions presenting as septic shock in a late preterm infant. J Pediatric Infectious Dis 2012;7:131-4.

7. Tiraboschi IC, Niveyro C, Mandarano AM, et al. Congenital candidiasis: confirmation of mother-neonate transmission using molecular analysis techniques. Med Mycol 2010;48:177-81.

8. DiGiulio DB, Romero R, Amogan HP, et al. Microbial prevalence, diversity and abundance in amniotic fluid during preterm labor: a molecular and culture-based investigation. PLoS ONE 2008;3:e3056.

9. Rode ME, Morgan MA, Ruchelli E, Forouzan I. Candida chorioamnipnitis after serial therapeutic amniocenteses: a possible association. J Perinatol 2000;20:335-7.

10. Bean LM, Jackson JR, Dobak WJ, Beiswenger TR, Thorp JA. Intra-amniotic fluconazole therapy for Candida albicans intra-amniotic infection. Obstet Gynecol 2013;121:Suppl 1:452-4.

11. Mendling W, Brasch J. Guideline vulvovaginal candidosis (2010) of the german society for gynecology and obstetrics, the working group for infections and infectimmunology in gynecology and obstetrics, the german society of dermatology, the board of german dermatologists and the german speaking mycological society. Mycoses 2012;55:Suppl 3:1-13.

12. Roberts CL, Rickard K, Kotsiou G, Morris JM. Treatment of asymptomatic vaginal candidiasis in pregnancy to prevent preterm birth: an open-label pilot randomized controlled trial. BMC Pregnancy Childbirth 2011;11:18.

13. Cotch MF, Hillier SL, Gibbs RS, Eschenbach DA. Epidemiology and outcomes associated with moderate to heavy Candida colonization during pregnancy. Vaginal Infections and Prematurity Study Group. Am J Obstet Gynecol 1998;178:374-80.

14. Czeizel AE, Fladung B, Vargha P. Preterm birth reduction after clotrimazole treatment during pregnancy. Eur J Obstet Gynecol Reprod Biol 2004;116:157-63.

15. Kiss H, Petricevic L, Husslein P. Prospective randomised controlled trial of an infection screening programme to reduce the rate of preterm delivery. BMJ 2004;329:371. 
16. Snyder CC, Wolfe KB, Gisslen T, et al. Modulation of lipopolysaccharideinduced chorioamnionitis by Ureaplasma parvum in sheep. Am J Obstet Gynecol 2013;208:399.e1-8.

17. Moss TJ, Nitsos I, Knox CL, et al. Ureaplasma colonization of amniotic fluid and efficacy of antenatal corticosteroids for preterm lung maturation in sheep. Am J Obstet Gynecol 2009;200:96.e1-6.

18. Kallapur SG, Nitsos I, Moss TJ, et al. IL-1 mediates pulmonary and systemic inflammatory responses to chorioamnionitis induced by lipopolysaccharide. Am J Respir Crit Care Med 2009;179:955-61.

19. Moss TJ, Knox CL, Kallapur SG, et al. Experimental amniotic fluid infection in sheep: effects of Ureaplasma parvum serovars 3 and 6 on preterm or term fetal sheep. Am J Obstet Gynecol 2008;198:122.e1-8.

20. Moss TJ, Nitsos I, Ikegami M, Jobe AH, Newnham JP. Experimental intrauterine Ureaplasma infection in sheep. Am J Obstet Gynecol 2005;192:1179-86.

21. Wolfs TGAM, Kallapur SG, Knox CL, et al. Antenatal ureaplasma infection impairs development of the fetal ovine gut in an IL-1-dependent manner. Mucosal Immunol 2013;6:547-56.

22. Kemp MW, Saito M, Kallapur SG, et al. Inflammation of the fetal ovine skin following in utero exposure to Ureaplasma parvum. Reprod Sci 2011;18:1128-37.

23. Kallapur SG, Kramer BW, Knox CL, et al. Chronic fetal exposure to Ureaplasma parvum suppresses innate immune responses in sheep. J Immunol 2011;187:2688-95.

24. Carrara MA, Donatti L, Damke E, Svidizinski TI, Consolaro ME, Batista MR. A new model of vaginal infection by Candida albicans in rats. Mycopathologia 2010;170:331-8.

25. Clemons KV, Spearow JL, Parmar R, Espiritu M, Stevens DA. Genetic susceptibility of mice to Candida albicans vaginitis correlates with host estrogen sensitivity. Infect Immun 2004;72:4878-80.

26. Fidel PL Jr, Lynch ME, Sobel JD. Candida-specific cell-mediated immunity is demonstrable in mice with experimental vaginal candidiasis. Infect Immun 1993;61:1990-5.

27. Kemp MW, Kannan PS, Saito M, et al. Selective exposure of the fetal lung and skin/amnion (but not gastro-intestinal tract) to LPS elicits acute systemic inflammation in fetal sheep. PLoS ONE 2013;8:e63355.
28. Kramer BW, Moss TJ, Willet KE, et al. Dose and time response after intraamniotic endotoxin in preterm lambs. Am J Respir Crit Care Med 2001;164:982-8.

29. Zhu W, Filler SG. Interactions of Candida albicans with epithelial cells. Cell Microbiol 2010;12:273-82.

30. Kallapur SG, Willet KE, Jobe AH, Ikegami M, Bachurski CJ. Intra-amniotic endotoxin: chorioamnionitis precedes lung maturation in preterm lambs. Am J Physiol Lung Cell Mol Physiol 2001;280:L527-36.

31. Kemp MW, Saito M, Nitsos I, Jobe AH, Kallapur SG, Newnham JP. Exposure to in utero lipopolysaccharide induces inflammation in the fetal ovine skin. Reprod Sci 2011;18:88-98.

32. Watterberg KL. Adrenocortical function and dysfunction in the fetus and neonate. Semin Neonatol 2004;9:13-21.

33. Challis JR, Dilley SR, Robinson JS, Thorburn GD. Prostaglandins in the circulation of the fetal lamb. Prostaglandins 1976;11:1041-52.

34. Newnham JP, Moss TJ, Nitsos I, Sloboda DM. Antenatal corticosteroids: the good, the bad and the unknown. Curr Opin Obstet Gynecol 2002;14:607-12.

35. Benjamin DK Jr, DeLong ER, Steinbach WJ, Cotton CM, Walsh TJ, Clark RH. Empirical therapy for neonatal candidemia in very low birth weight infants. Pediatrics 2003;112(3 Pt 1):543-7.

36. Dyke MP, Ott K. Severe thrombocytopenia in extremely low birthweight infants with systemic candidiasis. J Paediatr Child Health 1993;29:298301.

37. Kim MJ, Romero R, Gervasi MT, et al. Widespread microbial invasion of the chorioamniotic membranes is a consequence and not a cause of intraamniotic infection. Lab Invest 2009;89:924-36.

38. Innings A, Ullberg M, Johansson A, et al. Multiplex real-time PCR targeting the RNase P RNA gene for detection and identification of Candida species in blood. J Clin Microbiol 2007;45:874-80.

39. Bustin SA, Benes V, Garson JA, et al. The MIQE guidelines: minimum information for publication of quantitative real-time PCR experiments. Clin Chem 2009;55:611-22.

40. Zhang L, Saito M, Jobe A, et al. Intra-amniotic administration of E coli lipopolysaccharides causes sustained inflammation of the fetal skin in sheep. Reprod Sci 2012;19:1181-9. 